\title{
Is Canada ready for therapeutic vaccines?
}

Cite as: CMAJ 2017 January 23;189:E133-4. doi: 10.1503/cmaj.109-5370

W ithin five years, the first 16 of an expected onslaught of therapeutic vaccines will be licensed in the United States. Another 140 are in clinical trials. They are mostly aimed at treating cancers (105), but also allergies (13) and other diseases (25). There are even ones for smoking cessation and cocaine abuse. A handful are also being developed by Canadian vaccine companies.

Like all drugs, therapeutic vaccines will go through the usual Health Canada approval process, but less certain is which agency will conduct the expert evidencebased review to determine which therapeutic vaccines should be publicly funded.

"Are we prepared?" asks Robert Van Exan, a Canadian cell biologist who has worked in the vaccine industry for 35 years. "My purpose is to stimulate people to start thinking and talking about this before it hits us." He spoke about this need at the 2016 Canadian Immunization Conference in Ottawa.

Unlike traditional vaccines, which prevent an infectious disease, therapeutic vaccines provide treatment for a chronic disease or condition. But the moniker vaccine is appropriate because, like preventive vaccines, therapeutic vaccines deliver an antigen. But rather than jumpstarting the immune system to prevent disease, they stimulate the immune system to do other things, explains Van Exan, who now works as a consultant. In the case of cancers, an antigen can stimulate the body's immune system to attack a tumour.

In Canada, the National Advisory Committee on Immunization (NACl) provides evidence on the use of vaccines in humans to the Public Health Agency of Canada, which gives advice to provincial ministries of health, who make decisions on public coverage. But $\mathrm{NACl}$ deals with vaccines for

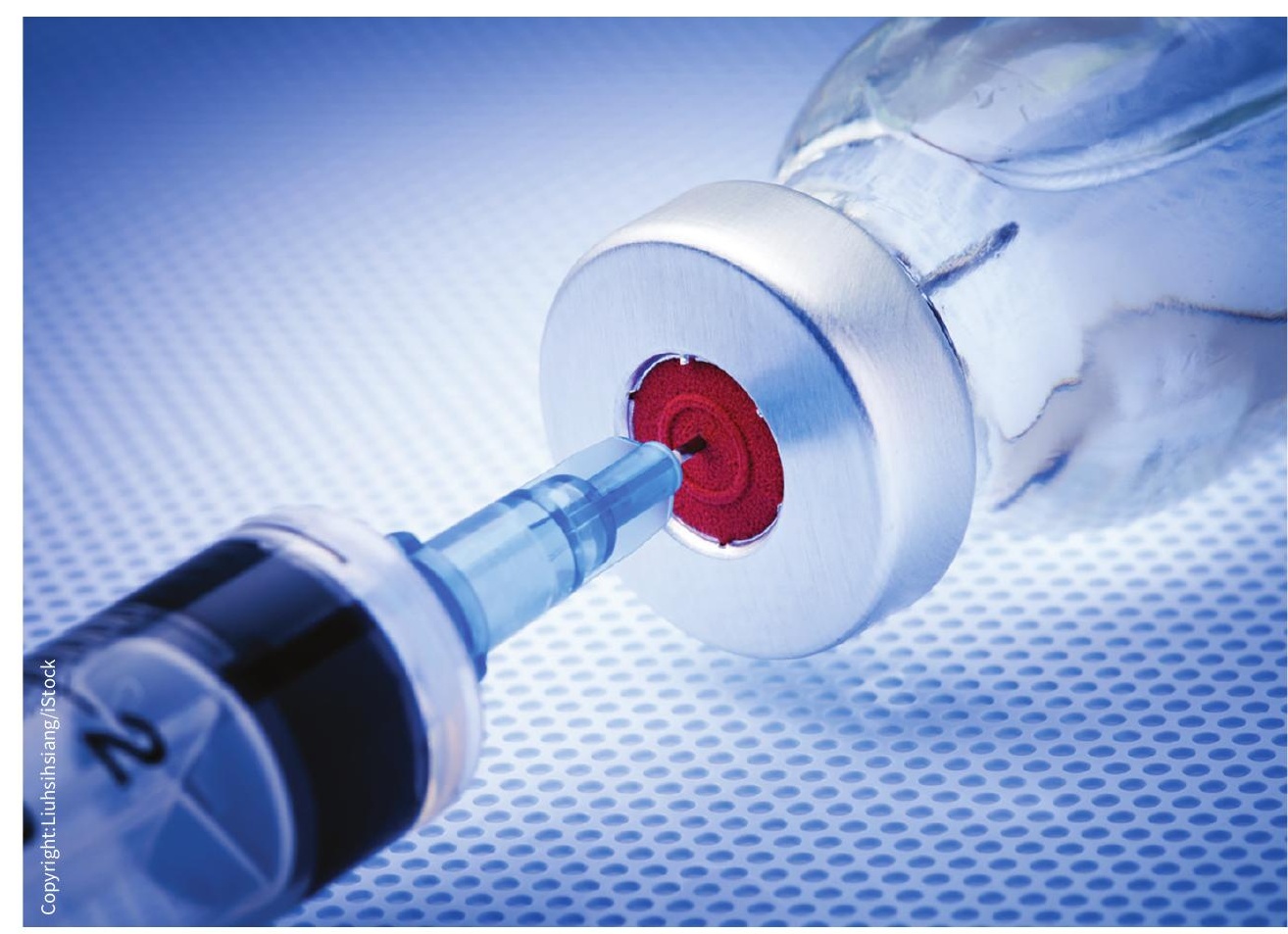

No one has decided who will present evidence on which therapeutic vaccines should be publicly funded.

infectious diseases, not things like monoclonal antibody treatment for Crohn disease and other diseases, points out NACI Chair Dr. Ian Gemmill.

"These don't come to $\mathrm{NACl}$ at all; these and therapeutics are for a very different purpose," says Gemmill. In addition, NACI currently approves only one or two vaccines a year and doesn't have the member expertise or the capacity to assess therapeutic vaccines.

So, where does that leave them?

"What we need to do is to have those conversations to see exactly where they lie. You don't want them to be orphaned," says Robert Lerch, executive secretary of the National Advisory Committee on Immunization Secretariat, at the Centre for Immunization and Respiratory Infectious Diseases with the Public Health Agency of
Canada. "It may turn out that there is more than one category of therapeutics."

Various partners will be involved in that conversation, adds Lerch. "We'll be on the list with other groups. Does it make sense that this come to [NACl]? Well no, but if not here, then where?"

The responsibility could fall to the Canadian Agency for Drugs and Technology in Health (CADTH) or the Pan-Canadian Oncology Drug Review (pCODR).

Alexandra Chambers, director of pCODR, which is part of CADTH, says "nothing's happened yet."

"Therapeutic vaccines have definitely come up in conversation," Chambers adds. "But decisions around who will review them haven't been made."

She says CADTH will stick to its usual process, waiting for provincial ministries 
of health to request a review. "Demand [to the ministries] comes from patients, patient groups or industry. The drug plans are pretty savvy; they see what else is happening internationally, they see the pressures on the horizon."

CADTH might be better positioned than $\mathrm{NACl}$ to do evaluations, Van Exan says.
"But do they have resources and expertise? What criteria are they using? Are these the right criteria?"

Van Exan is particularly concerned about how long approval might take. "Getting through $\mathrm{NACl}$ and government regulation, procurement and into programs ... can take a decade. My fear is if we haven't sorted it out then everything will get delayed and access for doctors to use these new technologies will get delayed and that would be a crying shame."

"It's time to get it on the table," he said.

Barbara Sibbald, CMAJ 